\title{
Review
}

\section{Dissecting complex traits: recent advances in hypertension genomics Kevin M O'Shaughnessy}

Address: Clinical Pharmacology Unit, Department of Medicine, Box 110, Addenbrooke's Hospital, Cambridge, CB2 2QQ, UK. Email:kmo22@medschl.cam.ac.uk

Published: 28 April 2009

Genome Medicine 2009, I:43 (doi: 10.1 186/gm43)

The electronic version of this article is the complete one and can be found online at http://genomemedicine.com/content///4/43

(C) 2009 BioMed Central Ltd

\begin{abstract}
Genome-wide association scans are beginning to identify risk alleles for a number of complex diseases and traits. Essential hypertension looked as though it would be an exception to this trend after the Wellcome Trust Case Control Consortium data were published in 2007. However, more recent scans and meta-analyses have reversed the fortunes of essential hypertension. A number of loci have been identified, including a new antihypertensive drug target in the guise of the serine/threonine kinase SPAK. This kinase forms part of a novel kinase cascade that regulates the NCCT $\left(\mathrm{Na}^{+} / \mathrm{Cl}^{-}\right.$co-transporter; $\left.\mathrm{SLCl} 2 \mathrm{A3}\right)$ in the kidney and is defective in a rare Mendelian hypertension syndrome (Gordon's syndrome). Genome-wide scans are also being used to look for alleles to predict individual response to antihypertensive drugs and their risk of causing side-effects. The results of these are expected in the near future and may finally deliver the long-awaited goal of personalized drug therapy for hypertensive patients.
\end{abstract}

\section{Introduction}

The idea that blood pressure (BP) and (by definition) hypertension are polygenic traits arose half a century ago from the famous debate between George Pickering and Robert Platt about the nature of the frequency distribution of BP [1].

Many epidemiological studies have subsequently confirmed the heritability of BP; however, its inheritance is not Mendelian as Platt believed, but rather complex. In fact the major diseases of industrialized societies, including obesity, diabetes, and coronary artery disease (CAD), have complex genetics. The favored model for these complex diseases is often referred to as the 'common disease-common variant' hypothesis (CD-CV), in which each susceptibility locus in the human genome for a complex disease is explained by a single (or a handful of) gene variant(s) or allele(s) [2]. This relatively simple allelic architecture, of many susceptibility genes but few variants of each gene, has not been extensively tested. Some loci do fall neatly into this classification, such as the ApoE locus in CAD [3] and PPARG in type 2 diabetes
[4], which have single coding variants. However, others, such as the NOD2 locus in Crohn's disease [4] or the calpain 10 (CAPN1O) locus in type 2 diabetes [5], cannot be explained so simply. To date, the problem for essential hypertension has been more fundamental, with a difficulty in confidently identifying any susceptibility loci. Linkagebased approaches have been used, but they require family structures that are difficult to recruit in very large numbers. Even when linked loci have been identified [6], there remains the formidable task of finding a functional variant within a locus that perhaps covers a substantial fraction of a chromosome and contains hundreds of genes.

\section{The hypertension genome-wide association study comes of age}

In contrast to the difficulties of using linkage, association studies are ideally suited for chasing putative CD-CV gene variants. Initially, association studies explored individual candidate genes, but key genomic discoveries and 
technological advances in the last decade have changed this. First was the discovery of widespread genomic variation in the form of single nucleotide polymorphisms (SNPs). These occur on average every few hundred bases along the genome, and their mapping under the Hapmap project has provided a detailed framework of genomic variation across the entire genome [7]. Second has been the technology to genotype hundreds of thousands of SNPs on a single 'chip'. Together, these have led to the genome-wide association study (GWAS) becoming commonplace as a method to dissect complex diseases and traits. The problem with association studies has, however, always been their poor record of reproducibility [8]. The reasons for this are manifold, including poor matching of cases and controls; hidden stratification in the populations; allelic and genetic heterogeneity; differences in environmental effects between populations; different attributable risks to an allele in different populations; and differences in an allele's frequency between populations. The lack of power in many studies has also been an important contributor to both false-negative and falsepositive GWAS results.

Two GWAS in hypertension were published during 2007, but these were disappointing. The Framingham Heart Study (FHS) reported on 1,327 individuals whose BP had been sampled longitudinally in the Framingham community project [9], and the Wellcome Trust Case Control Consortium (WTCCC) reported results from 2,00o Northern European subjects with hypertension [10]. The WTCCC used a denser SNP coverage of the genome than the FHS (300K versus $100 \mathrm{~K}$ ), but lacked BP data to look for quantitative trait effects. Nevertheless, neither study could identify SNPs that achieved genome-wide statistical significance $\left(P<5 \times 10^{-7}\right)$ - a necessary cut-off because of the multiple testing involved. A handful of SNPs did achieve $P$ values of $<10^{-5}$ in both studies, but none of these SNPs were common to the two studies. With hindsight, there were difficulties in the WTCCC, especially in its controls, which were not specifically selected for BP. Instead, they represented a common set of controls used for all seven common diseases considered by the WTCCC, so it is likely that a significant minority of the controls were in fact hypertensive. The chip used in the WTCCC (itself substantially better than the $100 \mathrm{~K}$ used by the FHS) also poorly tagged some of the candidates previously reported to associate or link with hypertension. This was certainly the case for the WNK1 gene (With No K-lysine deficient protein kinase 1), which has attracted a lot of attention in the past few years. Mutations in this novel serine/threonine kinase, along with $\mathrm{WNK}_{4}$, have provided the molecular basis for Gordon's syndrome, a rare Mendelian form of familial hypertension and hyperkalemia [11]. The UK BRItish Genetics of HyperTension (BRIGHT) consortium initially reported association of the $W N K 1$ promoter with $\mathrm{BP}$ in essential hypertension [12], a result that was replicated in a longitudinal study of BP in childhood [13]. The poor tagging of WNK1 has improved with newer chips, and obviously the problem can be tackled by imputation. Nevertheless, the $W N K$ genes have not emerged as candidates from subsequent GWAS.

The FHS and WTCCC GWAS results were disappointing since they suggested that hypertension really could lack susceptibility alleles with effect sizes as large as those in other complex diseases such as type 2 diabetes and obesity (odd ratios 1.2-1.5) [14,15]. An attempt was made to replicate the six SNPs that achieved highest significance in hypertension $\left(5 \times 10^{-7}<P<10^{-5}\right)$ in the WTCCC sample, by using 12,593 individuals from the Family Blood Pressure Program [16]. In fact, they could only replicate one of them (rs1937506), and although the effect on systolic BP was large, it went in opposite directions in different ethnic subgroups (Americans of Hispanic versus European ancestry). There is also the issue that this SNP sits in a $500 \mathrm{~K}$ bp gene desert with no obvious gene sitting in linkage disequilibrium (LD) with it.

In 2009, the first GWAS reporting SNP hits that achieve genome-wide statistical significance were published $[17,18]$. Their replication outside of the primary discovery cohort gives added reassurance that these may be true positive hits. The KORA (Kooperative Gesundheitsforschung in der Region Augsburg) GWAS [17] was based on a south German cohort and identified a SNP upstream of the $\mathrm{CDH} 13$ gene, rs11646213, that encodes the T-cadherin adhesion molecule. This membrane-bound receptor is involved in angiogenesis and can function as an adiponectin receptor, so it is biologically plausible. Importantly, this SNP was replicated in two further European cohorts, although not in the UK BRIGHT cohort. The $\mathrm{CDH}_{13}$ gene was also highlighted in the secondary analysis of the 10oK FHS GWAS (rs3096277) [9], so it merits close follow-up.

The second GWAS to report a genome-wide significant hit used an Amish cohort and identified a novel candidate gene in the form of STK39, a serine/threonine kinase called SPAK (STE20/SPS1-related proline- and alanine-rich kinase) [18]. This is an intriguing result for two reasons. Firstly, SPAK and related kinases are known to regulate the activity of cation/chloride transporters, including the $\mathrm{Na}^{+} / \mathrm{Cl}^{-}$cotransporter NCCT, in the distal convoluted tubule (DCT) of the kidney [19]. SPAK appears to activate NCCT by phosphorylating key residues in its amino-terminal region, so functional SPAK variants will affect salt uptake by the DCT and hence BP. Secondly, SPAK itself is a phosphorylation target for upstream WNK kinases, mutations of which are now known to form the molecular basis for Gordon's syndrome. So this very rare Mendelian BP syndrome of saltdependent hypertension and hyperkalemia has led to the discovery of a regulatory phosphorylation cascade that harbors a polygenic BP trait. This offers the real prospect that blocking one of these kinases could lead to a novel class of antihypertensive drug. This is perhaps ironic given that 
most large pharmaceutical companies have abandoned drug development in this therapeutic area.

In common with recent experience from other complex diseases and traits, combining datasets in meta-analyses gives the power to robustly probe their allelic structure. The Global BPgen consortium has recently reported the results of a GWAS meta-analysis using 34,433 subjects, which is an order of magnitude larger than any of the single-cohort GWAS preceding it [20]. They have identified no less than eight loci with obvious candidate genes and some of these hits (in the region of $C Y P 17 A 1, C Y P 1 A 2$ and $F G F 5$ ) carry very high levels of significance $\left(P<10^{-20}\right)$ indeed. The hits identified were the same whether BP was analyzed as a quantitative trait or the dichotomous trait of hypertension, which may have surprised some and reassured others. However, it is also notable that these hits do not include any of the genome-wide significant hits reported elsewhere. Global BPgen is clearly setting the new benchmark for GWAS in hypertension. A second consortium, the CHARGE (Cohorts for Heart and Aging Research in Genomic Epidemiology) consortium, is set to publish its own meta-analysis shortly. It has a slightly larger cohort of 38,00o [21] and it is hoped there will be overlap of its hits with Global BPgen. Only time will confirm whether or not this is the case.

\section{Refining the GWAS leads}

In comparison to the problems of unraveling essential hypertension, the rare Mendelian forms of high and low BP are now relatively well understood, with causative mutations identified in some 20 different genes [22]. Most of these genes affect salt handling by the kidney and can have a large effect, in the range of several tens of millimeters of mercury, on the BP of affected individuals. However, functional variants in these genes are probably not a major influence on the BP within the general population. Hence, the resequencing of the genes for three of these Mendelian forms of BP (SLC12A3, SLC12A1 and KCNJ1) in the FHS cohort identified known or putative functional mutations in just 49 of the 3,095 subjects screened [23]. The mutations did substantially affect the BP of the carriers (up to 6-8 $\mathrm{mmHg}$ ), but all had a frequency of $<1 / 2,000$. So, it seems that for essential hypertension the CV-CD hypothesis is still largely intact.

A striking feature of the SNPs identified in GWAS in complex diseases over the past few years is how small a proportion of disease variability is explained by them. So, the problem for the future will be to identify hypertension alleles that may be rare, possibly poorly penetrant and certainly of low attributable risk (odds ratios $<1.2$ and accounting for $<1 \mathrm{mmHg}$ of $\mathrm{BP}$ ). The effects of some of these alleles will also be conditional on interactions with other alleles and environmental factors such as salt loading. An insight into this problem is recent work showing association of BP and hypertension with two common SNPs in the NPPA and $N P P B$ gene cluster encoding the atrial natriuretic peptide (ANP) and the brain natriuretic peptide (BNP) [24]. The association with plasma levels of these peptides was first established using the FHS cohort. Using this intermediate trait, the authors then used a Mendelian randomization approach to show that these SNPs predicted systolic BP (SBP) and diastolic BP (DBP), as well as the incidence of hypertension across several cohorts totaling >30,000 subjects. However, the effect size was small (minor alleles of rs5068 and rs198358 explained 0.9-1.5 mmHg for SBP and $0.3-0.8 \mathrm{mmHg}$ for DBP) and the SNPs are in the 3'untranslated region, so how they functionally affect expression of the $N P P A / B$ genes is unclear. There was also an interesting lesson in that the researchers initially found a non-synonymous SNP in the coding region that strongly associated with ANP levels. However, this turned out to be an artifact because it changed an amino acid in the aminoterminal end of the pro-peptide that was measured by their original assay kit. The effect disappeared when they used a kit measuring mature peptide lacking this amino-terminal pro-sequence.

The report from Newton-Cheh et al. [24] highlights the effort required to robustly explore just a single susceptibility locus for hypertension. Taking forward hits from the recent GWAS calls for very large sample sizes (in the approximately $100 \mathrm{~K}$ range or perhaps beyond), which may not be practical or financially viable and thus suggests that other strategies are needed. The use of pathway analysis reported recently by Torkamani et al. is one such strategy [25]. Using the SNP $P$-values from the WTCCC to weight $>15,000$ genes, they generated gene networks that suggested pathogenic pathways for the common diseases in the WTCCC. Many of these were biologically very plausible and interconnected, but often not the 'usual suspects' in terms of candidate gene lists. For example, for hypertension, the most over-represented pathway was glutamate-regulated signaling through the D1A receptor. Many of the other hypertension pathways had significant overlap with those identified for CAD. This is not surprising, but emphasizes that we should expect extensive overlap in the risk alleles for the two diseases. Pathway analysis is definitely a technique to watch.

\section{Using GWAS to predict individual response to antihypertensive therapy and the risk of adverse drug reactions}

The large variation in individual $\mathrm{BP}$ responses to antihypertensive drugs is a significant clinical problem, and being able to predict this would be an enormous aid to treatment optimization. Part of the variation can be explained by factors such as age, sex, ethnicity and renin status. Common polymorphisms in the CYP2D6 gene have also been important historically in determining the pharmacokinetics of some antihypertensive drugs (for example, debrisoquine and beta-blockers such as metoprolol), but the 
pharmacokinetics of more recent antihypertensive drugs are not affected by CYP2D6 metabolizer status. This implies that a large proportion of the individual variability in drug response is pharmacodynamic (that is, it involves the drugresponse pathway) and is genetically determined. The genetics can of course be expected to be complex.

To date, genetic influences on the pharmacodynamics of antihypertensive drug action have been studied in detail in only a few cases. These include the indel in the ACE gene and non-synonymous SNPs in the gene encoding the $\beta_{1}$ adrenoceptor, $A D R B 1$. Plasma angiotensin-converting enzyme (ACE) levels are regulated in part by the insertion/deletion (I/D) polymorphism in intron 16 of the $A C E$ gene, with DD homozygotes having roughly twice the ACE levels of II homozygotes [26]. However, there is no consensus on whether this polymorphism affects either untreated BP or its response to the introduction of an ACE inhibitor [27,28]. The situation with the non-synonymous SNPs in ADRB1 is perhaps a little clearer. They affect the amino acids encoded at positions 49 and 389 , which substantially alters $\beta_{1}-$ receptor function in vitro [29]. The fall in BP after dosing with metoprolol is consistently predicted by the ADRB1 genotype, with carriers of an arginine at position 389 behaving as good responders [30,31]. However, there is no consensus on the impact of these SNPs on the response of the resting or exercise-induced heart rate to beta-blocker therapy [32,33]. Exercise-induced heart rates are a robust index of $\beta_{1}$-receptor activation in vivo, so these differences are probably attributable to patient selection and small sample sizes.

The GWAS approach can be obviously applied to the discovery of alleles that affect drug response, and several of these are under way. For example, the PEAR study (Pharmacogenomic Evaluation of Antihypertensive Responses) is part of the National Institutes of Health (NIH) PharmacoGenomics Research Network [34], and is looking for alleles that predict the BP response to a thiazide and beta-blocker in a prospective cohort of 800 hypertensive subjects [35]. This prospective study may seem large, but from experience with GWAS it is probably only powered to deliver modest to large allele effects. Its results are not expected until 2010.

Predicting the short-term hemodynamic effect of an antihypertensive drug is, of course, not the only goal. Since hypertension treatment is initiated to prevent cardiovascular end-points, it should be possible to predict these end-points based on a patient's genotype. A recent report based on the outcome data in the INVEST (International Verapamil SRTrandolapril Study) antihypertension trial has successfully done just this [36]. The authors were able to show that the $A D R B 1$ genotype predicted total mortality in a three-year follow-up period, with the ${ }^{49} \mathrm{Ser}-{ }^{389} \mathrm{Arg}$ haplotype conferring a significant hazard ratio of 3.7. Importantly, this risk was only seen among subjects randomized to the non-betablocker arm, while those randomized to the beta-blocker arm (atenolol) had complete protection. In fact, phase III hypertension drug trials are a potentially invaluable source of outcome data for this sort of analysis, hence the interest in submitting cohorts such as ASCOT (Anglo-Scandinavian Cardiac Outcome Trial) to gene chip interrogation [37]. Thus, there is an expectation that we may soon have GWAS data to address the task of identifying alleles that predict an individual's response to a given antihypertensive drug class and treatment outcome. The task would be greatly helped if there was some way of tapping into the mine of pharmacogenomic data collected at various stages of the preclinical drug development process by the pharmaceutical industry. Historically, these companies have been reluctant to give the regulatory bodies sight of these data, although several years ago the US Food and Drug Administration (FDA) stated the data would not prejudice the drug registration process [38]. Nevertheless, a public safe-harbor and repository for these data is still awaited.

We still have a very long way to go, but pharmacogenomics is moving us closer to personalized prescribing of antihypertensive drugs. We need to be able to identify the drugs an individual is most likely to respond to as well as predict the risk of adverse drug reactions (ADRs) to the same drugs. The expectation is that this will increase compliance, which remains a major obstacle to reducing many individuals' BP to internationally agreed target levels. The use of pharmacogenomic data to predict ADRs is evolving rapidly. There have been some notable recent successes using the GWAS approach - for example, in predicting individual risk of myositis on statin therapy [39] or the risk of bradycardia when using beta-blockers [40].

\section{Conclusions}

In the past year, landmark GWAS have appeared that convincingly show the existence of susceptibility genes or loci for essential hypertension. Many more are expected as more datasets are meta-analyzed. Like other complex diseases, the next hurdle will be to identify the functional gene variants. This is a formidable task since it is likely that many of these loci will be complex in their local operation as well as in their interaction with other loci and the environment. However, they promise to provide novel insights into the molecular pathways involved as well as new drug targets. One of these has already been identified in the form of a previously little known kinase called SPAK. However, in terms of managing hypertension in the clinic we already have enough 'drugged' BP targets. What is needed is a more rational approach to using the drugs we have, and the delivery of personalized medicine is the much-anticipated spin-off from current GWAS research in this area. It remains to be seen whether this improves on the current empirical approaches such as the 'ABCD' rule [41]. 


\begin{abstract}
Abbreviations
ACE, angiotensin-converting enzyme; ADR, adverse drug reaction; ANP, atrial natriuretic peptide; ASCOT, AngloScandinavian Cardiac Outcome Trial; BP, blood pressure; BRIGHT, BRItish Genetics of HyperTension; CAD, coronary artery disease; $\mathrm{CD}-\mathrm{CV}$, common disease-common variant; CHARGE, Cohorts for Heart and Aging Research in Genomic Epidemiology; DBP, diastolic blood pressure; DCT, distal convoluted tubule; FDA, Food and Drug Administration; FHS, Framingham Heart Study; GWAS, genomewide association study/studies; I/D, insertion/deletion; INVEST, International Verapamil SR-Trandolapril Study; KORA, Kooperative Gesundheitsforschung in der Region Augsburg; LD, linkage disequilibrium; NCCT, $\mathrm{Na}^{+} / \mathrm{Cl}^{-}$cotransporter (SLC12A3); NIH, National Institutes of Health; PEAR, Pharmacogenomic Evaluation of Antihypertensive Responses; SBP, systolic blood pressure; SNP, single nucleotide polymorphism; SPAK, STE20/SPS1-related proline- and alanine-rich kinase; WNK, With No-lysine (=K) kinase; WTCCC, Wellcome Trust Case Control Consortium.
\end{abstract}

\section{Competing interests}

The author declares that he has no competing interests.

\section{Acknowledgements}

The author would like to thank the British Heart Foundation (BHF) for grant support.

\section{References}

I. Swales JD: Platt Versus Pickering: an Episode in Recent Medical History. Cambridge: Keynes Press; 1985.

2. Reich DE, Lander ES: On the allelic spectrum of human disease. Trends Genet 200I, I7:502-5I0.

3. Bennet AM, Di Angelantonio E, Ye Z, Wensley F, Dahlin A, Ahlbom A, Keavney B, Collins R, Wiman B, de Faire U, Danesh J: Association of apolipoprotein e genotypes with lipid levels and coronary risk. JAMA 2007, 298:1300-1311.

4. Ogura $Y$, Bonen DK, Inohara N, Nicolae DL, Chen FF, Ramos R, Britton H, Moran T, Karaliuskas R, Duerr RH, Achkar JP, Brant SR, Bayless TM, Kirschner BS, Hanauer SB, Nunez G, Cho JH: A frameshift mutation in NOD2 associated with susceptibility to Crohn's disease. Nature 2001, 41 I:603-606.

5. Horikawa Y, Oda N, Cox NJ, Li X, Orho-Melander M, Hara M, Hinokio $Y$, Lindner TH, Mashima H, Schwarz PEH, del Bosque-Plata L, Horikawa Y, Oda Y, Yoshiuchi I, Colilla S, Polonsky KS, Wei S, Concannon P, Iwasaki N, Schulze J, Baier LJ, Bogardus C, Groop L, Boerwinkle E, Hanis CL, Bell Gl: Genetic variation in the gene encoding calpain-10 is associated with type 2 diabetes mellitus. Nat Genet 2000, 26:163-175.

6. Caulfield M, Munroe P, Pembroke J, Samani N, Dominiczak A, Brown M, Benjamin N, Webster J, Ratcliffe P, O'Shea S, Papp J, Taylor E, Dobson R, Knight J, Newhouse S, Hooper J, Lee W, Brain N, Clayton D, Lathrop GM, Farrall M, Connell J: Genome-wide mapping of human loci for essential hypertension. Lancet 2003, 361:21 I82123.

7. The International HapMap Project [http://www.hapmap.org].

8. Salanti G, Sanderson S, Higgins JP: Obstacles and opportunities in meta-analysis of genetic association studies. Genet Med 2005, 7:1 3-20.

9. Levy D, Larson M, Benjamin E, Newton-Cheh C, Wang T, Hwang SJ, Vasan R, Mitchell G: Framingham Heart Study I00K Project: genome-wide associations for blood pressure and arterial stiffness. BMC Med Genet 2007, 8:S3.
10. The Wellcome Trust Case Control Consortium: Genome-wide association study of 14,000 cases of seven common diseases and 3,000 shared controls. Nature 2007, 447:66I-678.

II. Kahle KT, Ring AM, Lifton RP: Molecular physiology of the WNK kinases. Annu Rev Physiol 2008, 70:329-355.

12. Newhouse SJ, Wallace C, Dobson R, Mein C, Pembroke J, Farrall M, Clayton D, Brown M, Samani N, Dominiczak A, Connell JM, Webster J, Lathrop GM, Caulfield M, Munroe PB: Haplotypes of the WNKI gene associate with blood pressure variation in a severely hypertensive population from the British Genetics of Hypertension study. Hum Mol Genet 2005, I4: I805-I8|4.

13. Tobin MD, Raleigh SM, Newhouse S, Braund P, Bodycote C, Ogleby J, Cross D, Gracey J, Hayes S, Smith T, Ridge C, Caulfield M, Sheehan NA, Munroe PB, Burton PR, Samani NJ: Association of WNKI gene polymorphisms and haplotypes with ambulatory blood pressure in the general population. Circulation 2005, I I 2:3423-3429.

14. Scuteri A, Sanna S, Chen WM, Uda M, Albai G, Strait J, Najiar S, Nagaraja R, Orru M, Usala G, Dei M, Lai S, Maschio A, Busonero F, Mulas A, Ehret GB, Fink AA, Weder AB, Cooper RS, Galan $P$, Chakravarti A, Schlessinger D, Cao A, Lakatta E, Abecasis GR: Genome-wide association scan shows genetic variants in the FTO gene are associated with obesity-related traits. PLoS Genet 2007, 3:ell5.

15. Loos RJF, Lindgren CM, Li S, Wheeler E, Zhao JH, Prokopenko I, Inouye M, Freathy RM, Attwood AP, Beckmann JS, Berndt SI, Bergmann S, Bennett AJ, Bingham SA, Bochud M, Brown M, Cauchi S, Connell JM, Cooper C, Smith GD, Day I, Dina C, De S, Dermitzakis ET, Doney ASF, Elliott KS, Elliott P, Evans DM, Sadaf Farooqi I, Froguel $P$, et al.: Common variants near $M C 4 R$ are associated with fat mass, weight and risk of obesity. Nat Genet 2008, 40:768-775.

16. Ehret GB, Morrison AC, O'Connor AA, Grove ML, Baird L, Schwander K, Weder A, Cooper RS, Rao DC, Hunt SC, Boerwinkle E, Chakravarti A: Replication of the Wellcome Trust genome-wide association study of essential hypertension: the Family Blood Pressure Program. Eur J Hum Genet 2008, 16:1507-15II.

17. Org E, Eyheramendy S, Juhanson P, Gieger C, Lichtner P, Klopp N, Veldre G, Doring A, Viigimaa M, Sober S, Tomberg K, Eckstein G, KORA, Kelgo P, Rebane T, Shaw-Hawkins S, Howard P, Onipinla A Dobson RJ, Newhouse SJ, Brown M, Dominiczak A, Connell J, Samani N, Farrall M, BRIGHT, Caulfield MJ, Munroe PB, Illig T, Wichmann $\mathrm{HE}$, et al:: Genome-wide scan identifies $C D H / 3$ as a novel susceptibility locus contributing to blood pressure determination in two European populations. Hum Mol Genet 2009, [Epub ahead of print].

18. Wang Y, O'Connell JR, McArdle PF, Wade JB, Dorff SE, Shah SI, Shi $X$, Pan L, Rampersaud E, Shen H, Kim JD, Subramanya AR, Steinle NI, Parsa A, Ober CC, Welling PA, Chakravarti A, Weder AB, Cooper RS, Mitchell BD, Shuldiner AR, Chang YP: From the cover: wholegenome association study identifies STK39 as a hypertension susceptibility gene. Proc Natl Acad Sci USA 2009, 106:226-23I.

19. Richardson C, Rafiqi FH, Karlsson HKR, Moleleki N, Vandewalle A, Campbell DG, Morrice NA, Alessi DR: Activation of the thiazidesensitive $\mathrm{Na}^{+}-\mathrm{Cl}^{-}$- cotransporter by the WNK-regulated kinases SPAK and OSRI. J Cell Sci 2008, I2I:675-684.

20. Christopher Newton-Cheh, Toby Johnson, Vesela Gateva, Martin D Tobin, Murielle Bochud, Lachlan Coin, Samer S Najjar, Jing Hua Zhao, Simon C Heath, Susana Eyheramendy, Konstantinos Papadakis: Eight blood pressure loci identified by genome-wide association study of 34,433 people of European ancestry. Nat Genet 2009, in press.

21. Psaty BM, O'Donnell CJ, Gudnason V, Lunetta KL, Folsom AR, Rotter JI, Uitterlinden AG, Harris TB, Witteman JCM, Boerwinkle E, on behalf of the CHARGE Consortium: Cohorts for Heart and Aging Research in Genomic Epidemiology (CHARGE) Consortium: Design of prospective meta-analyses of genome-wide association studies from 5 cohorts. Circ Cardiovasc Genet 2009, 2:73-80.

22. Lifton RL: Genetic dissection of human blood pressure variation: common pathways from rare phenotypes. Harvey Lect 2004, 100:71 101.

23. Ji W, Foo JN, O'Roak BJ, Zhao H, Larson MG, Simon DB, NewtonCheh C, State M, Levy D, Lifton RP: Rare independent mutations in renal salt handling genes contribute to blood pressure variation. Nat Genet 2008, 40:592-599.

24. Newton-Cheh C, Larson MG, Vasan RS, Levy D, Bloch KD, Surti A, Guiducci C, Kathiresan S, Benjamin EJ, Struck J, Morgenthaler NG, Bergmann A, Blankenberg S, Kee F, Nilsson P, Yin X, Peltonen L, Vartiainen E, Salomaa V, Hirschhorn JN, Melander O, Wang TJ: Association of common variants in NPPA and NPPB with circulating 
natriuretic peptides and blood pressure. Nat Genet 2009, 41:348353.

25. Torkamani A, Topol EJ, Schork NJ: Pathway analysis of seven common diseases assessed by genome-wide association. Genomics 2008, 92:265-272.

26. Tiret L, Rigat B, Visvikis S, Breda C, Corvol P, Cambien F, Soubrier F: Evidence, from combined segregation and linkage analysis, that a variant of the angiotensin l-converting enzyme $(A C E)$ gene controls plasma ACE levels. Am J Hum Genet 1992, 51:197-205.

27. Filigheddu F, Argiolas G, Bulla E, Troffa C, Bulla P, Fadda S, Zaninello R, Degortes S, Frau F, Pitzoi S, Glorioso N: Clinical variables, not RAAS polymorphisms, predict blood pressure response to ACE inhibitors in Sardinians. Pharmacogenomics 2008, 9:14 19-1427.

28. Hingorani AD, Jia H, Stevens PA, Hopper R, Dickerson JE, Brown MJ: Renin-angiotensin system gene polymorphisms influence blood pressure and the response to angiotensin converting enzyme inhibition. $J$ Hypertens 1995, 13:1602-1609.

29. Sandilands A, O'Shaughnessy KM: The functional significance of genetic variation within the betal-adrenoceptor. $\mathrm{Br} J$ Clin Pharmacol 2005, 60:235-243

30. Johnson JA, Zineh I, Puckett BJ, McGorray SP, Yarandi HN, Pauly DF: $\beta I-A d r e n e r g i c$ receptor polymorphisms and antihypertensive response to metoprolol. Clin Pharmacol Ther 2003, 74:44-52.

31. Liu I, Liu ZQ, Tan ZR, Chen XP, Wang LS, Zhou G, Zhou HH: Gly389Arg polymorphism of $\beta \mathrm{I}$-adrenergic receptor is associated with the cardiovascular response to metoprolol. Clin Pharmacol Ther 2003, 74:372-379.

32. O'Shaughnessy KM, Fu B, Dickerson C, Thurston D, Brown MJ: The gain-of-function G389R variant of the betal-adrenoceptor does not influence blood pressure or heart rate response to beta-blockade in hypertensive subjects. Clin Sci 2000, 99:233-238.

33. Beitelshees AL, Zineh I, Yarandi HN, Pauly DF, Johnson JA: Influence of phenotype and pharmacokinetics on $\beta$-blocker drug target pharmacogenetics. Pharmacogenomics J 2006, 6: I74-I78.

34. The PharmacoGenomics Knowledge Base [http://www.pharmgkb.org/index.jsp].

35. Johnson JA, Boerwinkle E, Zineh I, Chapman AB, Bailey K, CooperDeHoff RM, Gums J, Curry RW, Gong Y, Beitelshees AL, Schwartz G, Turner ST: Pharmacogenomics of antihypertensive drugs: Rationale and design of the Pharmacogenomic Evaluation of Antihypertensive Responses (PEAR) study. Am Heart / 2009, 157:442-449.

36. Pacanowski MA, Gong Y, Cooper-DeHoff RM, Schork NJ, Shriver MD, Langaee TY, Pepine CJ, Johnson JA: $\beta$-Adrenergic receptor gene polymorphisms and $\beta$-blocker treatment outcomes in hypertension. Clin Pharmacol Ther 2008, 84:71 5-72I.

37. The Anglo-Scandiniavian Cardiac Outcome Trial [http://www.ascotstudy.org/home.htm]

38. Lesko LJ, Salerno RA, Spear BB, Anderson DC, Anderson T, Brazell C, Collins J, Dorner A, Essayan D, Gomez-Mancilla B, Hackett J, Huang SM, Ide S, Killinger J, Leighton J, Mansfield E, Meyer R, Ryan SG, Schmith V, Shaw P, Sistare F, Watson M, Worobec A: Pharmacogenetics and pharmacogenomics in drug development and regulatory decision making: report of the first FDA-PWG-PhRMA-DruSafe Workshop. J Clin Pharmacol 2003, 43:342-358.

39. The SEARCH Collaborative Group: SLCOIBI Variants and statininduced myopathy - a genomewide study. N Engl J Med 2008, 359:789-799.

40. Bijl MJ, Visser LE, van Schaik RHN, Kors JA, Witteman JCM, Hofman A, Vulto AG, van Gelder T, Stricker BHC: Genetic variation in the CYP2D6 gene is associated with a lower heart rate and blood pressure in $\beta$-blocker users. Clin Pharmacol Ther 2008, 85:45-50.

4I. Williams B, Poulter NR, Brown MJ, Davis M, Mclnnes GT, Potter JF, Sever PS, Thom SM: British Hypertension Society guidelines for hypertension management 2004 (BHS-IV): summary. BMJ 2004, 328:634-640. 